\title{
LOW ENERGY PART OF THE CONCERT HIGH-POWER PROTON LINAC
}

\author{
R. Ferdinand, B. Aune, P-Y. Beauvais, R. Duperrier, M. Desmons, R. Gobin, P. Gros, J-L. Laclare, \\ J-M. Lagniel, N. Pichoff, D. Uriot, CEA-Saclay, France \\ K. Bongardt, R. Maier, S. Martin, Y. Senichev, Forschungszentrum Julich GmbH, Germany \\ H. Klein, A. Schempp, IAP, Johann Wolfgang Goethe-Universität, Frankfurt am Main, Germany
}

\section{Abstract}

The $1.3 \mathrm{GeV}$ Linac of the CONCERT multi-users facility has to accelerate protons and $\mathrm{H}^{-}$ions in a series of current pulses distributed over each $20 \mathrm{~ms}$ period. The peak current is identical for all pulses to keep the space charge forces about constant apart from a slight emittance change between $\mathrm{H}^{+}$and $\mathrm{H}^{-}$bunches. The beam power required for a given application is then obtained by adjusting the pulse duration with a total maximum power of $20 \mathrm{MW}$ and $5 \mathrm{MW}$ for the proton and $\mathrm{H}^{-}$beams respectively. The reference design of the low-energy part of this linac is made-up of two separate proton and $\mathrm{H}^{-}$ injectors up to $23 \mathrm{MeV}$, the $\mathrm{H}^{-}$one using a funnelling system. These injectors are followed by a series of copper cavities up to the transition with superconducting cavities at about $185 \mathrm{MeV}$. The overall architecture, the technical choices and the beam dynamics in this high-power proton linac front end are presented and discussed.

\section{INTRODUCTION}

The CONCERT [1,2] (COmbined Neutron Centre for European Research and Technology) concept is that a long series of applications could benefit from the performances of the next generation of High Power Proton Accelerators. These new accelerators should produce beams of several tens of MW. They could act as proton factories, with the protons being used to create large fluxes of neutrons, other hadrons such as pions, muons, neutrinos and exotic ions. The production of Tritium or radio-isotopes is not considered. The 5 most important applications are :

- Condensed matter studies by neutron scattering (ESS)

- Nuclear physics - study of Rare Ion Beams (RIBs)

- Accelerator Driven Transmutation (ADT) of longlived radioactive waste

- Technological Irradiation Tool (TIT) - test of materials

- Particle physics (muon colliders, neutrino factories)

The CONCERT project aims at combining these applications on the same site with a single accelerator. One of the tasks was therefore to evaluate whether a technically achievable solution could exist which would be more cost-effective than a series of stand-alone facilities. The $25 \mathrm{MW}$ total power considered for the feasibility study take into account the ESS long pulse option (5MW proton beam).

\section{PRINCIPLES}

The linac parameters are defined to match user requirements with a transparent cohabitation. In addition to be excellent at the design level in terms of reliability, availability and flexibility, the driver has to be robust and based on well-proven technologies. A major concern in the design of the linac is the minimisation of beam losses $(<1 \mathrm{~W} / \mathrm{m})$ in order to avoid activation of the machine and irradiation of the environment.

The design also takes into account the following points:

- Have the same space charge level and emittances for $\mathrm{H}^{-}$and protons in the common part of the linac

- Minimise the demands on the $\mathrm{H}^{-}$sources

- Independent $\mathrm{H}^{+}$and $\mathrm{H}^{-}$tunings ahead of the funnel

- Minimise the risks on the most difficult accelerator components (chopper, funnel, etc...)

The reference design of the low energy part of the linac (room temperature) was defined during a meeting held in Jülich in December 2000. The conclusions lead to the scheme described in Figure 1.

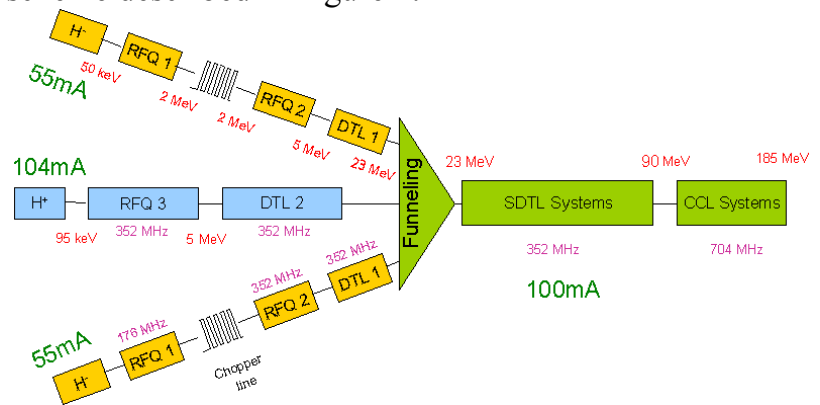

Figure 1: CONCERT Low Energy Linac scheme

The main difficulties remain the two $\mathrm{H}^{-}$sources, the chopper lines, RFQ2, RFQ3 and DTL2 $\left(\mathrm{H}^{+}\right)$and the funnelling system. Another difficult point is the beam dynamics, which must allow easy beam matching at all transitions (avoid emittance growth and halo formation).

\section{FREQUENCY}

The choice of the RF frequencies for the low and high energy parts of the linac is determined by:

1- The frequency of the low energy structures should allow large enough RFQ and DTL cavities for installation of the water-cooling systems and for the use of electromagnetic quadrupoles in the first drift tubes of the DTL. Since low frequencies lead to bigger cavities, the frequency of the proton linac low energy part is usually between $200 \mathrm{MHz}$ and $350 \mathrm{MHz}$. The choice of a slightly higher frequency as for SNS $(400 \mathrm{MHz})$ is obviously possible with the use of permanent magnets in the DTL as well as a long focussing period (ffoddo for SNS). But this 
leads to matching and emittance growth problems due to stronger radial/longitudinal couplings.

2- The optimum frequency of the superconducting cavities is somewhere around $1000 \mathrm{MHz}$ (TTF, Tesla cavities). The frequency can be lower but not below $600-650 \mathrm{MHz}$ to keep a high efficiency using $2 \mathrm{~K}$ superfluid helium.

The choice of the optimum frequencies is then determined by the choice of the frequency jump:

- $\times 2$ lead to choose the highest possible frequency for the low energy linac: $350 \mathrm{MHz}$ to stay as high as possible in the lower part of the high-energy linac frequency range $(700 \mathrm{MHz})$.

- $\times 3$ lead to less constraints $(260 / 780 \mathrm{MHz}$, $300 / 900 \mathrm{MHz}$ or more) but has not be accepted to avoid beam dynamics problems (bunch compression).

The couple $352 / 704 \mathrm{MHz}$ was chosen as the best compromise. It allows using the $350 \mathrm{MHz}$ high power tube already in use in accelerators (CERN). The $\mathrm{H}^{-}$ sources currents imply the use of a funnel to get the right final beam current. The funnel line for $\mathrm{H}^{-}$implies to double the frequency, leading to $176 \mathrm{MHz}$ in RFQ1. This frequency jump is done in RFQ2, because RFQs are perfectly suited to efficiently bunch a beam. Other advantages of the $176 \mathrm{MHz}$ choice at low energy are longer rise/fall times of the fast choppers and lower space charge effects in RFQ1.

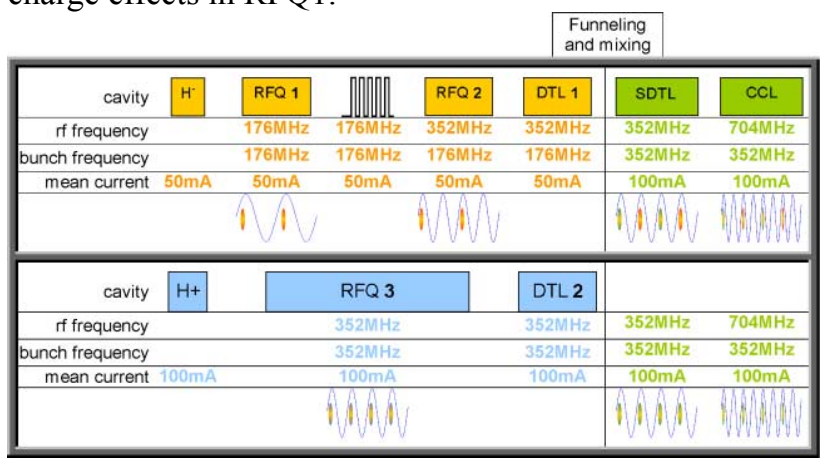

Figure 2: Sketch of the RF bucket filling

\section{H' SOURCES}

The negative ion sources were recognized as a major concern. A long lifetime source ( $>$ month) does not exist today, and the accumulation of requirements (emittances, current, duty cycle, repetition rate, lifetime...) is a big challenge. The present studies and the work done for other project like SNS let us expect to reach the ESS short pulse requirements but not more. Table 1 describes the $\mathrm{H}^{-}$ and $\mathrm{H}^{+}$sources requests.

\section{5. $\mathrm{H}^{+}$SOURCE}

The requirement of the $100 \mathrm{~mA}$ proton source with $20 \%$ duty cycle makes it close to a cw design. In the past years, a considerable effort was invested in the development of high current $\mathrm{cw}$ proton sources. The LEDA project $[3,4]$ at the Los Alamos National Laboratory has already demonstrated a successful routine $\mathrm{cw}$ operation at $110 \mathrm{~mA}$. The SILHI source of the IPHI project [5] shows similar performance as well as a simultaneous excellent availability (in excess of $99 \%$ during a 136 hour-test).

Table 1: CONCERT Source requirements.

\begin{tabular}{l|l|l}
\hline \multicolumn{1}{c|}{ Parameter } & \multicolumn{1}{c}{ H sources } & \multicolumn{1}{c}{$H^{+}$source } \\
\hline Duty cycle & $5 \%$ & $20 \%$ \\
\hline Repetition rate & $50 \mathrm{~Hz}$ & $50 \mathrm{~Hz}$ \\
\hline Max pulse length & $1 \mathrm{~ms}$ & $2.5 \mathrm{~ms}$ \\
\hline Beam current & $60 \mathrm{~mA}$ & $110 \mathrm{~mA}$ \\
\hline $\begin{array}{l}\text { rms norm. beam } \\
\text { emittance }\end{array}$ & $0.2 \pi . \mathrm{mm} . \mathrm{mrad}$ & $0.2 \pi . \mathrm{mm} . \mathrm{mrad}$ \\
\hline $\begin{array}{l}\text { X and Y planes } \\
\text { emit. differences }\end{array}$ & $0-10 \%$ & na \\
\hline Beam energy & $50 \mathrm{keV}$ & $95 \mathrm{keV}$ \\
\hline Species fraction & $\mathrm{na}$ & $>90 \%$ \\
\hline Beam noise & $< \pm 1 \% \mathrm{rms}$ & $< \pm 1 \% \mathrm{rms}$ \\
\hline Source type & $?$ & $\mathrm{ECR}$ \\
\hline Reliability & $>95 \%$ & $>98 \%$ \\
\hline
\end{tabular}

\section{RFQs}

The RFQs bunch and accelerate the $\mathrm{H}^{+}$and $\mathrm{H}^{-}$beam extracted from the sources up to $5 \mathrm{MeV}$. This energy is chosen as the lowest energy compatible with the technical feasibility of the first electro magnetic (EM) quadrupoles in the following Drift Tube Linac (DTL) structure. The RFQs of the $\mathrm{H}^{+}$and $\mathrm{H}^{-}$branch are necessarily different. The proton line has to operate with a higher duty cycle ( $\sim 20 \%$ ), while the $\mathrm{H}^{-}$lines RFQs have to be split into two parts (RFQ1 and RFQ2) to allow the insertion of the chopper line. The specifications of RFQ3 $\left(\mathrm{H}^{+}\right)$are more demanding: high reliability at higher beam current $(100 \mathrm{~mA})$, longer duty cycle $(\sim 20 \%)$ and higher frequency $(352 \mathrm{MHz})$. Fortunately, recent progresses were made in the field of long duty cycle (up to cw) $350 \mathrm{MHz}$ four-vane RFQs totally relevant for CONCERT $[4,5]$. The designs of the RFQs (see Table 2) were done using PARMTEQM and TOUTATIS [7].

Table 2 : RFQ Beam dynamics results

\begin{tabular}{l|l|l|l}
\hline \multicolumn{1}{c|}{ Parameter } & \multicolumn{1}{c}{$R F Q 1$} & \multicolumn{1}{c}{$R F Q 2$} & \multicolumn{1}{c}{$R F Q 3$} \\
\hline Input current & $55 \mathrm{~mA}$ & $\begin{array}{l}54 \mathrm{~mA} \\
(108 \mathrm{for} \mathrm{sc})\end{array}$ & $100 \mathrm{~mA}$ \\
\hline Transmission & $100 \%$ & $99.9 \%$ & $99.7 \%$ \\
\hline Frequency & $176 \mathrm{MHz}$ & $352 \mathrm{MHz}$ & $352 \mathrm{MHz}$ \\
\hline $\begin{array}{l}\text { Input emit }(r m s \\
\text { norm, } \pi . m m . m r a d)\end{array}$ & 0.30 & 0.32 & 0.25 \\
\hline Trsv. emit. increase & $2 \%$ & $3 \%$ & $1 \%$ \\
\hline Length & $5.98 \mathrm{~m}$ & $5.18 \mathrm{~m}$ & $7.93 \mathrm{~m}$ \\
\hline Max Kilpatrick & 1.8 & 1.71 & 1.7 \\
\hline Type & $4-$-Rods & $4-$-Vanes & 4 -Vanes \\
\hline
\end{tabular}

\section{CHOPPER AND CHOPPER LINE}

The transition energy between RFQ1 and RFQ2 should not be too low to limit the debunching in the chopper line, and not too high to limit the chopper voltage. Classically, this transition is between 2 and $3 \mathrm{MeV}$. The lower limit of $2 \mathrm{MeV}$ was chosen to avoid unnecessary activation in the preceding structure and problems in the chopper line. The 
chopper field will be raised between 2 bunches. The choice of $176 \mathrm{MHz}$ and $2 \mathrm{MeV}$ for RFQ1 then relax constrains on the chopper (rise time shorter than $3.8 \mathrm{~ns}$ with jitter and no need for an anti-chopper). The $2.6 \mathrm{~m}$ long chopper line shows an emittance increase of $3.4 \%$, $2.7 \%$ and $4.2 \%$ in the $\mathrm{X}, \mathrm{Y}$, and $\mathrm{Z}$ planes. The transmissions equals $98.8 \% / 0.003 \%$ for the $0 / 1150 \mathrm{~V}$ chopper deviation.

\section{DTLS BEFORE THE FUNNEL LINE}

An intense R\&D effort is done within the IPHI Project $[5,6]$ to demonstrate the feasibility of the first EM quadrupoles in the first Drift Tubes. Conventional magnets will allow the fine tuning needed for a better matching control and halo limitation. A conventional DTL structure at $352 \mathrm{MHz}$ has quite high shunt impedance.

\section{FUNNEL}

The funnel is the most complicated section of the linac. The energy at which funnel is done is a compromise between lower beam rigidity at low energy and lower space-charge effects along the beam transport at high energy. The choice for the CONCERT funnel energy is $23 \mathrm{MeV}$. To achieve the $\pm 10^{\circ}$ deflection angle requirement, an attractive funnel cavity is proposed by Y. Senichev [8].

\section{SDTL-CCL}

Large apertures are needed to achieve a loss free beam transport. Downstream the funnel, $704 \mathrm{MHz}$ cavities would then have a lower shunt impedance compare to $352 \mathrm{MHz}$ structures. The effective shunt impedance along the structures has been compared for $352 \mathrm{MHz}$ DTLs and SDTLs and $704 \mathrm{MHz}$ CCLs. $90 \mathrm{MeV}$ appears to be a good transition energy to a CCL structure. The $352 \mathrm{MHz}$ SDTL structure is cheaper and is more forgiving with regards to alignment. There is no need for post couplers. Above all, it offers tuning possibilities in the longitudinal plane and easier beam dynamics.

Above $50 \mathrm{MeV}$, the effective shunt impedance of SDTL structures (especially the transit-time factor) goes down rapidly, and it becomes interesting to switch to a Coupled Cavity Linac (CCL). A preliminary cost optimisation has shown that the optimum $\mathrm{E}_{0} \mathrm{~T}$ is around $2.5-3 \mathrm{MV} / \mathrm{m}$ (this optimum is flat between 2 and $4 \mathrm{MV} / \mathrm{m}$, and weakly dependant of the duty cycle). Transition energy to the superconducting (sc) cavities depends on equilibrium between the power losses in hot CCL, and the sc cavities efficiency. Below $\beta=0.5$, stiffness and vibrations problems arise. The accelerator length stays the same and new problems come up, so there is low interest in using sc cavities below $185 \mathrm{MeV}$.

\section{END-TO-END SIMULATION}

Full current and zero current simulations were done for the accelerator. The end-to-end simulations start with a 4D-waterbag input distribution at the RFQs input
( $\varepsilon=0.30 \pi . \mathrm{mm} . \mathrm{mrad}$ for $\mathrm{H}^{-}$and $\varepsilon=0.25 \pi . \mathrm{mm} . \mathrm{mrad}$ for $\mathrm{H}^{+}$). Computation indicates that particles are lost only in RFQ3 and chopper lines. The following rms normalized emittances are expected:

\begin{tabular}{c|c|c|c}
$r m s$ emittance & RFQ input & Funnel output & CCL output \\
\hline $\mathrm{H}^{+}$transverse & 0.25 & 0.30 & 0.32 \\
\hline $\mathrm{H}^{+}$longitudinal & -- & 0.45 & 0.43 \\
\hline $\mathrm{H}^{-}$transverse & 0.30 & 0.38 & 0.40 \\
\hline $\mathrm{H}^{-}$longitudinal & -- & 0.68 & 0.64
\end{tabular}

\section{SCHEMES}

Drawbacks and benefits were analysed for several architectures. No ideal scheme exists: the selected design is the best compromise.

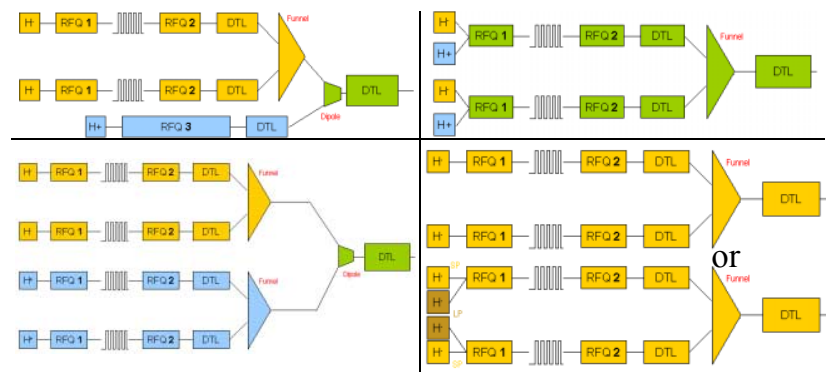

Figure 3: The different schemes studied

\section{CONCLUSION}

The feasibility studies of the room temperature part of the CONCERT linac show no stopper. The main difficulty requiring development is the $\mathrm{H}^{-}$sources. All the other technical hitches areas (chopper, funnel) don't seem beyond reach. The beam dynamics calculations are smooth, with phase advance continuities in the three planes. Full Monte Carlo error studies will complete the study.

\section{REFERENCES}

[1] CONCERT http://web.concert.free.fr

[2] A. Mosnier et al. "Feasability of CONCERT", this conference

[3] H.V. Smith et al., "Update On The Commissioning Of The Low-Energy Demonstration Accelerator (LEDA) Radio-Frequency Quadrupole (RFQ)", Proceeding 1999 ICFA Workshop on The Physics of High Brightness Beams, in press

[4] L.J. Rybarcyk et al, "LEDA Beam Operations Milestone and Observed Beam Transmission Characteristics", Proc. Linac 2000, Monterey, 2000.

[5] P-Y. Beauvais et al, "Status Report on the Saclay High-Intensity Proton Injector Project (IPHI)", Proc EPAC 2000, Vienna, 2000

[6] P-E. Bernaudin et al. "Design of the IPHI DTL", this conference

[7] R. Duperrier, "TOUTATIS, a radio frequency quadrupole code", Phys. Rev, ST, Acc \& B., dec. 2000.

[8] Y. Senichev "The resonant multi-gaps funnelling systems" ESS103-00-A, ISSN1433-559X, June 2000. 